\title{
Evaluation of person-centeredness in nursing homes after a palliative care intervention: pre- and post-test experimental design
}

\author{
Christina Bökberg ${ }^{1 *}$ (D) Lina Behm¹, Birgitta Wallerstedt ${ }^{2}$ and Gerd Ahlström ${ }^{1}$
}

\begin{abstract}
Background: The needs of care based on palliative principles are stressed for all people with progressive and/or life-limiting conditions, regardless of age and the place in which care is provided. Person-centred palliative care strives to make the whole person visible and prioritizes the satisfaction of spiritual, existential, social, and psychological needs to the same extent as physical needs. However, person-centred palliative care for older persons in nursing homes seems to be sparse, possibly because staff in nursing homes do not have sufficient knowledge, skills, and training in managing symptoms and other aspects of palliative care.

Methods: This study aimed to evaluate whether an educational intervention had any effect on the staff's perception of providing person-centred palliative care for older persons in nursing homes. Methods: A knowledgebased palliative care intervention consisting of five 2-h seminars during a 6-month period was implemented at 20 nursing homes in Sweden. In total, 365 staff members were participated, 167 in the intervention group and 198 in the control group. Data were collected using two questionnaires, the Person-centred Care Assessment Tool (P-CAT) and the Person-Centred Climate Questionnaire (PCQ-S), answered before (baseline) and 3 months after (follow-up) the educational intervention was completed. Descriptive, comparative, and univariate logistical regression analyses were performed.
\end{abstract}

Results: Both the intervention group and the control group revealed high median scores in all subscales at baseline, except for the subscale amount of organizational and environmental support in the P-CAT. The staff's high rating level of person-centred care before the intervention provides limited space for further improvements at follow-up.

Conclusion: This study shows that staff perceived that managers' and the organization's amount of support to them in their everyday work was the only area for improvement in order to maintain person-centred care. The experiences among staff are crucial knowledge in understanding how palliative care can be made person-centred in spite of often limited resources in nursing homes. The dose and intensity of education activities of the intervention model need to be tested in future research to develop the most effective implementation model.

Trial registration: NCT02708498. Date of registration 26 February 2016.

Keywords: Person-centred care, Palliative care, Nursing home, Older persons, Staff education

\footnotetext{
* Correspondence: christina.bokberg@med.lu.se

${ }^{1}$ Department of Health Sciences, Faculty of Medicine, Lund University, P.O.

Box 157, SE-221 00 Lund, Sweden

Full list of author information is available at the end of the article
}

(c) The Author(s). 2019 Open Access This article is distributed under the terms of the Creative Commons Attribution 4.0 International License (http://creativecommons.org/licenses/by/4.0/), which permits unrestricted use, distribution, and reproduction in any medium, provided you give appropriate credit to the original author(s) and the source, provide a link to the Creative Commons license, and indicate if changes were made. The Creative Commons Public Domain Dedication waiver (http://creativecommons.org/publicdomain/zero/1.0/) applies to the data made available in this article, unless otherwise stated. 


\section{Background}

Nursing homes are common sites for older persons $(>65$ years) to spend the last part of their lives, [1-3], when they often are suffering from complex and life-limiting conditions [4]. These circumstances require various palliative care needs such as relief from distressing symptoms (pain, anxiety, nausea) to reduce discomfort and promote quality of life until death $[1,5]$. Despite these needs, palliative care for older persons in nursing homes seems to be sparse $[4,6]$. The approach in both palliative and person-centred care is characterised by a holistic view of the person, and that the person should be supported to live a life with dignity. Person-centred palliative care strives to make the whole person visible and prioritizes the satisfaction of spiritual, existential, social, and psychological needs to the same extent as physical needs [7, 8]. According to Saunders \& Kastenbaum [9], a person in a palliative care context is regarded as a human being consisting of physical, mental, social, and spiritual dimensions [9]. Both palliative and person-centred care use partnership and shared decisions based on patient narratives as well as teamwork and documentation of quality of care $[8$, 10] for proper planning of the person's remaining life [8].

Palliative care should therefore be provided in a supportive care environment, i.e. a person-centred environment, where the older person and the family feel welcome, seen, and involved by the staff. The concept of a person-centred care environment includes both the physical and psychosocial environment $[7,8]$. However, several studies have pointed out that person-centred care is lacking [11-13], although staff perceive that they provide person-centred care [14]. These shortcomings may lead to experiences of unnecessary suffering and decreased quality of life at the final stage of life $[4,5]$ and suggest an urgent need to improve person-centred palliative care in nursing homes for older persons with chronic illnesses $[1,4,5,15]$.

Traditionally, palliative care has been provided in hospice settings by specialists to persons dying from incurable cancer while persons dying from other diagnoses do not have the same access to palliative care $[1,16]$. Yet, the needs of care according to palliative principles are applicable to all people with progressive and/or lifelimiting conditions, regardless of age [17] and the place in which care is provided [1].

The multiple morbidities, with complex needs, and symptoms that older persons often have, can make it difficult to identify and handle the last period of life $[18,19]$. Therefore, provision of person-centred palliative care for older persons requires both geriatric and palliative expertise. Previous studies found that staff in nursing homes taking care of older persons at the end of life did not talk about death and dying with the residents because of their own fear [20] and uncertainty of existential questions that were perceived as difficult and emotionally demanding tasks for which they lack competence [21]. One possible reason for this is that staff in nursing homes lack education about palliative and end-of-life care [22, 23], and staff do not have sufficient knowledge, skills, and training in managing symptoms and other aspects of palliative care [24-27]. Goddard, et al. [23] reported that staff requested education about palliative care and that they lacked the knowledge to be able to provide appropriate end-of-lifecare. This study's aim was to evaluate whether an educational intervention had any effect on the staff's perception of providing person-centred palliative care for older persons in nursing homes.

\section{Methods \\ Design}

This study is a part of the project "Implementation of Knowledge-based Palliative Care", abbreviated as the KUPA project from the Swedish name [28]. The KUPA project aimed to improve the person-centeredness of palliative care and the quality of life and participation of older persons in nursing homes and their next of kin in the care process. The KUPA project is designed from an implementation perspective, described in the previous study protocol for the project [28]. In this research approach a successful change in practice, depends on the interplay between several aspects: (1) effectiveness of the implementation strategies; (2) characteristics of the "implementation object"; (3) characteristics of the implementers; (4) the target population; and (5) the context of the implementation [28]. Therefore, the evaluation of the whole KUPA project addresses several different perspectives which will be reported in future papers; staff, managers, context [21], the older persons and their next of kin and also various barriers and facilitating aspects of the implementation [28].

This study, as part of KUPA project, used pre- and post-test experimental design to evaluate staff's perception of providing person-centred care in both an intervention and control group (clinical trial registration NCT02708498) [28]. The assessment consisted of two questionnaires, one concerning person-centred care and one person-centred climate, answered by staff before and 3 months after (follow-up) the implementation of the 6-month educational intervention, i.e. 9 months from baseline. The same intervals applied to the control nursing homes.

\section{Setting}

There are approximately 2300 nursing homes in Sweden, a country with a population of 10 million people. These are accommodations mainly for older persons ( $\geq 65$ years) who live in their own apartments with care and services provided around the clock. In 2016, approximately 104, 000 older persons lived in nursing homes, of those were 
$4 \%$ aged 65 years and $13 \%$ aged 80 years or more. Access to an apartment is based upon the older person's needs and assessed by a social worker in the municipality. Moving into a nursing home usually occurs when the older person is too sick or frail to be able to continue living in their previous home with home care services. The median age in Sweden to move into a nursing home is 86.2 years for women and 83.7 years for men. Most of the residents (67\%) are women [29]. The length of stay after moving into nursing homes (time until death) is decreasing [30], and almost one-third of older persons who move into a nursing home die within 6 weeks [4]. Staff at nursing homes mainly consists of nurse assistants, but other professions are also represented, such as registered nurses, physiotherapists, and occupational therapists [31].

\section{The knowledge-based palliative care intervention}

The knowledge-based palliative care intervention consisted of five 2-h educational seminars for staff and frontline managers at nursing homes. The seminars were based on two Swedish national documents on the key principles of palliative care: clinical practice guidelines by the Regional Cancer Centres in co-operation [32] and national guidance on government initiative by the National Board of Health and Welfare [8]. Both documents were based on the WHO definition of palliative care $[1,5,33]$ and are intended to improve the quality life for individuals and their families.

An educational booklet, with an uncomplicated language, was designed within the KUPA project to use as study material for staff. The booklet contained five themes: 1) the palliative approach and dignified care, 2) next of kin, 3) existence and dying, 4) symptom relief and 5) collaborative care. The booklet is available in an English version (Additional file 1). The content of the different seminars had a common core for each nursing home and space was left for discussions and questions connected to each of the themes in the booklet. The seminar groups were led by experienced registered nurses and researchers from the field of palliative and geriatric care. The intervention was implemented over a 6-month period during 2016-2017 in two different counties in south of Sweden, in 20 nursing homes. None of the participating nursing homes, have had workplace education or training in palliative care before the KUPA intervention. Eight to twelve staffs were included at each nursing home [28], and the mean score of staff participated in each seminar was 8 .

\section{Sampling and participants}

The selection of nursing homes was made through voluntary participation and resulted in a mixture of both larger (more than 100 residents) and smaller nursing homes (less than 25 residents) in the two counties, as well as nursing homes from both urban and rural areas [28].

The informants in this study, the staff, were recruited consecutively in equal numbers from both the intervention nursing homes and the control nursing homes. Of 1554 eligible staff, 693 staff consented to participate. Of those consented, 328 staff became drop-out related to declined continued participation, staff quitting or changed workplace, sick leave, maternal leave, or death $(n=$ 1). Altogether 365 staff participated, 167 in the intervention group and 198 in the control group (Fig. 1).

In both the intervention group (92\%) and the control group (95\%), the staff reported experience in general palliative care. In the intervention group, 13\% reported experience in specialist palliative care. The corresponding number in the control group was $10 \%$ (Table 1).

\section{Instruments}

The data collection was based on two questionnaires, the Person-centred Care Assessment Tool (P-CAT) and the Person-Centred Climate Questionnaire (PCQ-S).

The P-CAT consists of 13 items that measure the extent to which staff rate provided care and service as being person-centred. The instrument exists both in a staff version and a version for older persons. In this study, the version for staff was used. The instrument contains two subscales: 1) Extent of personalization care, containing eight items, and 2) Amount of organizational and environmental support, containing five items [34]. The first subscale reflects the intentions and actions of the staff to personalize care and prioritize of the interaction as well as provide the possibility for residents to make their own decisions. The second subscale includes factors in the environment and organization that can support or hinder personalization of care and the creation of a positive psychosocial culture. Informants are asked to respond on a five-pointLikert-scale ranging from 1 (disagree completely) to 5 (agree completely). The total score of the scale runs from 13 to 65, with higher values indicating a higher degree of person-centeredness. The Swedish version of the P-CAT has been found to be valid, reliable, and applicable for further use [34, 35]. In this sample, the Cronbach's alpha estimates were $\alpha 0.69$ for subscale 1 and $\alpha 0.78$ for subscale 2 .

The PCQ-S consists of 14 items and was used to assess to what extent the climate of the care environments was person-centred. PCQ exists in both a patient (PCQ$\mathrm{P})$ and a staff version (PCQ-S). In this study, the version for staff was used. PCQ-S has been shown to be a valid and reliable contribution for assessing to what extent the climate of care environments is person-centred [36]. The subscales are 1) Safety, consisting of five items, 2) Everydayness, consisting of five items, and 3) Сотmunity, consisting of four items. Informants are asked to 


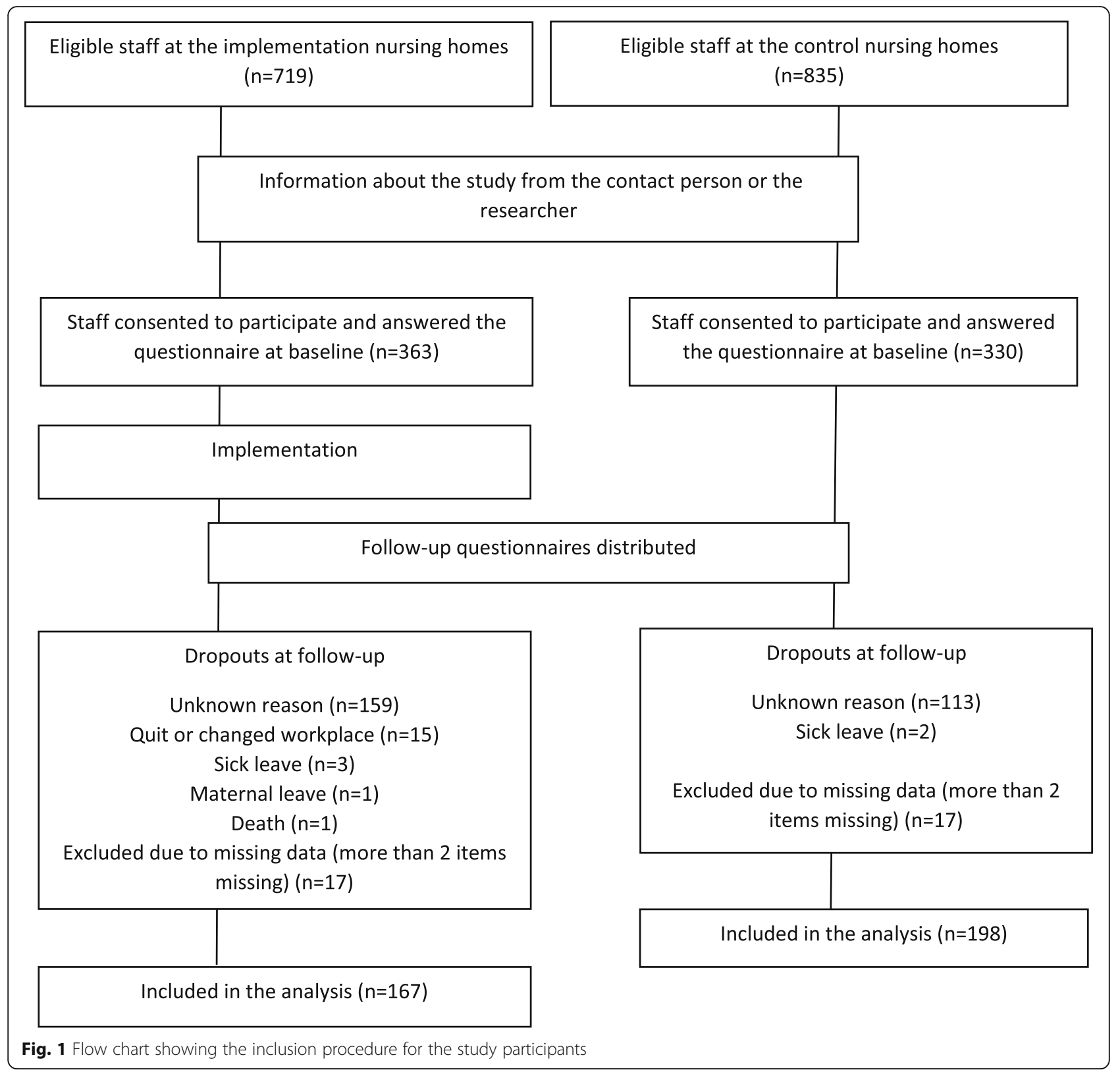

respond on a six-pointLikert-scale ranging from 1 (No, I disagree completely) to 6 (Yes, I agree completely). The total score of the scale runs from 14 (a climate that is minimally person-centred) to 84 (a climate that is maximally person-centred). In this sample, the Cronbach's alpha estimates were $\alpha 0.85$ for subscale $1, \alpha 0.90$ for subscale 2 , and $\alpha 0.86$ for subscale 3 .

\section{Data collection}

Before the start of the study, the researcher and the manager of the nursing homes informed the staff of the aim of the study and details of their participation. Then, a contact person, usually the frontline manager, was chosen at each nursing home. The contact person was responsible for the contact between the researcher and the staff. The researchers informed the contact person about the study. In some of the nursing homes, the contact person informed the staff about the study and in what way the staff would be involved, and in other nursing homes, the researchers were invited to present the study at regular meetings. It was stressed that participation was voluntary. Dates for distributing the questionnaires were decided in advance (with 6 months in between time points). The contact person distributed the questionnaires to the staff at the decided time. The inclusion criteria were having a permanent position at the nursing home as an assistant nurse, registered nurse, physiotherapist, occupational therapist, social worker, or 
Table 1 Characteristics of the staff in intervention and control

\begin{tabular}{lcl} 
group $(n=365)$ & \\
\hline Background variable & $\begin{array}{l}\text { Intervention group } \\
\text { (n 167) }\end{array}$ & $\begin{array}{l}\text { Control group } \\
\text { (n 198) }\end{array}$ \\
\hline $\begin{array}{l}\text { Age } \\
\text { median year (range) }\end{array}$ & $47(21-66)$ & $49(21-65)$ \\
Sex & & $9 / 189$ \\
Men/Women (number) & $10 / 157$ & \\
Working experience & & $14(0-41)$ \\
median year (range) & $11(0-44)$ & $179 / 90$ \\
Profession (n/\%) & & $8 / 4$ \\
Assistant nurse & $151 / 90$ & $2 / 1$ \\
Registered nurse & $8 / 5$ & $3 / 2$ \\
Occupational therapist & $2 / 1$ & $6 / 3$ \\
Physiotherapist & $1 / 0.5$ & $188 / 95$ \\
Frontline managers & $5 / 3$ & \\
Experience in general palliative care & $154 / 92$ & $20 / 10$ \\
yes (n/\%) & $21 / 13$ & \\
Experience in specialist palliative care & \\
yes (n/\%) & &
\end{tabular}

unit manager. The staff invited to participate received written information, a consent form, and the questionnaires. Locked mailboxes, one for the consent and one for the questionnaire, were placed at each nursing home. Based upon the response frequencies from the staff at each nursing home, the researcher provided several (up to 3 ) reminders to the contact person at both the baseline and follow-up.

\section{Statistical analyses}

The questionnaire data were analysed using methods applicable for within-group comparisons (data after intervention compared with data before in the intervention group and the control group). The selection of methods aside from descriptive statistics was based on whether the data were distributed normally and the scale level of the instruments. The Wilcoxon signed rank test was used to compare paired data within the groups. Furthermore, subgroup analyses within the intervention group to explore differences regarding between those who participated in the intervention and those who did not was performed. Either the Pearson chi-square test or Fisher's exact test (if any expected cell value was less than 5) was used. The Mann-WhitneyU-test and the Kruskal-Wallis test was applied to compare the baseline characteristics of the two groups.

Missing data on single items were replaced by the mean score for that item for the appropriate group [35]. Missing data of more than two items the questionnaire was excluded. To evaluate whether there were any differences in improvement between the study arms, the number of participants that had improved scores on the P-CAT and PCQ-S was compared at baseline and follow-up after intervention. In the final analysis, the participants were dichotomized into improved/not improved (same/or lower scores) from baseline to followup. A univariate logistic regression analysis was performed with the independent variable improvement/ non-improvement in P-CAT and PCQ-S and the dependent variable group (control/implementation). Changes were regarded as statistically significant if the two-tailed $p$ value was $<0.05$. Analyses were performed using IBM SPSS Statistics version 24.

\section{Results}

No statistically significant differences were detected between the two groups at baseline. The result indicates that the care and service provided at the nursing homes before the intervention had a person-centred approach with little room for improvement. All subscales at baseline in both the intervention group and the control group revealed high median scores, except for the subscale "Amount of organizational and environmental support" (P-CAT). This subscale includes the five items "I simply do not have the time to provide person-centred care", "The environment feels chaotic", "We have to get the work done before we can worry about a homelike environment", "The organization prevents me from providing person-centred care" and "It is hard for residents in the facility to find their way around".

\section{Pre- and post-asessment of P-CAT}

The overall results of the P-CAT showed no statistically significant changes in nursing home settings concerning person-centeredness after the KUPA intervention in either of the two subscales Extent of personalizing care and Amount of organizational and environmental support (Table 2). This result was the same when exploring differences between the staff that participated in the intervention with those who did not.

No differences in improvement were detected regarding person-centred care (P-CAT) compared to baseline. In Table 3, the proportion $\mathrm{n}(\%)$, the odds ratio (OR), the $95 \%$ confidence interval $(\mathrm{CI})$, and $p$-value for improvement from baseline to follow up in staff's perceptions of person-centred care and person-centred care climate between the study arms in the KUPA project are presented.

\section{Pre- and post-intervention assessment of PCQ-S}

PCQ-S was used to measure changes in the climate of the nursing homes settings concerning personcenteredness after implementation of the educational intervention. The results of the control group revealed 
close to a statistically significant decline (p 0.051) on the subscale Community. No statistically significant changes in the intervention group were detected for any of the three subscales (Table 2). This result was the same when exploring differences between the staff that participated in the intervention with those who did not.

No differences in improvement regarding personcentred care climate (PCQ-S) compared to baseline were detected (Table 3).

\section{Discussion}

This study aimed to evaluate whether an educational palliative care intervention for staff and frontline managers had any effect on their perception of providing person-centred care for older persons in nursing homes. Previous attempts at palliative care interventions at nursing homes are sparse, and, as far as we know, no study has previously used person-centred care as an outcome for evaluating a palliative care intervention even though person-centred care is a core concept in palliative care.

Our results showed no improvement in any of the outcomes (P-CAT or PCQ-S). This might imply that the intervention was not successful. The fact that our intervention did not focus on person-centred care explicitly might be one reason for the lack of improvement in the intervention group. However, there may be several other explanations for our results. One reason could be that the participants did not practice the knowledge learned from the intervention and this was an obstacle for disseminate knowledge about the intervention to their colleagues that not participated in the education seminars. One benefit with workplace training is the easy way of dissemination of knowledge to colleagues in comparison with course or conference education for one or a few persons at external location. Another reason could be the relationship between person-centred care and palliative care. Both person-centred care and palliative care are ambiguous concepts without a distinct consensus [37]. It has also been claimed that the ideal of personcentred care has not been integrated explicitly in palliative care [38] and that this integration seems to be even more challenged due to increasing needs for palliative care globally [37, 39]. However, Lavoie, Blondeau, \& Martineau [40] found that integration of a personcentred approach in palliative care contributed to a change where the care focus moved from being taskcentred to being person-centred. According to Grassi [41], a person-centred way of communication facilitates the ill person's understanding of the actual situation and the transition to palliative care. However, Öhlén et al. [37] argued that person-centred care is an ethical stance in palliative care.

Comparing our P-CAT results to other studies, staff at the included nursing homes in southern Sweden rate the person-centeredness in care similar to other studies in a nursing home context in Sweden [34] and in Norway, [42-44]. However, our rate was higher compared to nursing homes for persons with dementia in Sweden [45]. When comparing the results on person-centred climate (PCQ-S), our study showed high ratings compared to other Swedish studies in nursing homes [46], and nursing homes for persons with dementia [45].

A review of the literature [47] showed promising results of palliative care interventions on satisfaction with care, lower observed discomfort in residents with end-stage dementia, more referrals to hospice services, fewer hospital admissions and days in hospital and an increase in donot-resuscitate orders and documented advance care plan discussions. However, Froggatt [48] emphasized that a

Table 2 Intervention group ( $n=167)$ and control group $(n=198)$ analyses before and after intervention

\begin{tabular}{|c|c|c|c|c|c|c|}
\hline Scale and subscale & $\begin{array}{l}\text { Intervention group } \\
\text { Baseline Median (Q1- } \\
\text { Q3) }\end{array}$ & $\begin{array}{l}\text { Intervention group } \\
\text { Follow-up Median } \\
\text { (Q1-Q3) }\end{array}$ & $\begin{array}{l}\text { Significance } \\
\text { p-value }^{2}\end{array}$ & $\begin{array}{l}\text { Control group } \\
\text { Baseline Median } \\
\text { (Q1-Q3) }\end{array}$ & $\begin{array}{l}\text { Control group } \\
\text { Follow-up Median } \\
\text { (Q1-Q3) }\end{array}$ & $\begin{array}{l}\text { Significance } \\
p^{- \text {value }^{2}}\end{array}$ \\
\hline \multicolumn{7}{|l|}{$\mathrm{P}-\mathrm{CAT}^{3}$} \\
\hline Total (13-65) & $45.0(41.0-48.0)$ & $45.0(42.0-48.0)$ & 0.715 & $44.0(41.0-48.0)$ & $44.0(41.0-48.0)$ & 0.601 \\
\hline $\begin{array}{l}\text { Extent of personalizing } \\
\text { care }\left(8-40^{1}\right)\end{array}$ & 34. 0 (32.0-38.0) & $34.0(32.0-37.0)$ & 0.837 & $33.0(31.0-36.0)$ & $34.0(31.0-36.0)$ & 0.417 \\
\hline $\begin{array}{l}\text { Amount of organizational } \\
\text { and environmental } \\
\text { support }\left(5-25^{1}\right)\end{array}$ & $11.0(7.0-14.0)$ & $11.0(8.0-14.0)$ & 0.479 & $11.0(8.0-15.0)$ & $11.0(8.0-15.0)$ & 0.237 \\
\hline \multicolumn{7}{|l|}{$P C Q-S^{4}$} \\
\hline Total (14-84) & $77.0(68.0-82.0)$ & $77.0(68.0-81.0)$ & 0.685 & $71.0(61.0-80.0)$ & $74.0(67.0-79.0)$ & 0.451 \\
\hline $\operatorname{Safety}\left(5-30^{1}\right)$ & $28.0(25.0-30.0)$ & $27.0(25.0-30.0)$ & 0.942 & $27.0(25.0-29.0)$ & $27.0(24.0-29.0)$ & 0.693 \\
\hline Everydayness(5-30) & $26.0(22.0-29.0)$ & $25.0(22.0-29.0)$ & 0.494 & $24.0(21.0-28.0)$ & $25.0(21.0-28.0)$ & 0.374 \\
\hline Community $\left(4-24^{1}\right)$ & $23.0(21.0-24.0)$ & $23.0(20.0-24.0)$ & 0.280 & $22.0(22.0-24.0)$ & $22.0(21.0-24.0)$ & 0.051 \\
\hline
\end{tabular}

${ }^{1}$ Underlined score is the most favourable score. ${ }^{2}$ Wilcoxon Signed Rank Test. Q1 = first quartile; Q3 = third quartile. Significant values are bold. ${ }^{3}$ Missing $n=10$ in intervention group and $n=17$ in control group. ${ }^{4}$ Missing $n=22$ in intervention group and $n=33$ in control group 
Table 3 Improvement from baseline to follow-up between the study arms

\begin{tabular}{|c|c|c|c|c|c|c|}
\hline \multirow[t]{2}{*}{ Outcome measure } & \multicolumn{3}{|c|}{ Intervention group ( $n=167)$} & \multicolumn{3}{|c|}{ Control group $(n=198)$} \\
\hline & n (\%) & $\mathrm{OR}$ & $\mathrm{Cl}$ & n (\%) & OR & p-value \\
\hline \multicolumn{7}{|l|}{ P-CAT ${ }^{1}$} \\
\hline Extent of personalizing care & $69(44)$ & 1.115 & $0.734-1.695$ & $76(42)$ & 1 & 0.717 \\
\hline Amount of organizational and environmental support & $75(48)$ & 1.406 & $0.926-2.135$ & $72(40)$ & 1 & 0.108 \\
\hline \multicolumn{7}{|l|}{$P C Q-S^{2}$} \\
\hline Safety & $54(37)$ & 0.828 & $0.490-1.400$ & $66(40)$ & 1 & 0.482 \\
\hline Everydayness & $52(36)$ & 0.594 & $0.343-1.030$ & $74(45)$ & 1 & 0.064 \\
\hline Community & $57(39)$ & 1.081 & $0.068-1.861$ & $66(40)$ & 1 & 0.778 \\
\hline
\end{tabular}

${ }^{1}$ Missing $n=10$ in intervention group and $n=17$ in control group. ${ }^{2}$ Missing $n=22$ in intervention group and $n=33$ in control group

cultural change is needed to bring sufficient changes in practice at nursing homes to achieve evidence-based palliative care and that education alone is not sufficient. The intervention in our study was designed as a palliative education in five seminars. The dose of the educational intervention, during the implementation period of 6 months, was probably too small to create a change in the care culture and may have contributed to the lack of improvement. The importance of culture was evident in other studies [49-51], but philosophy and organization of care also governed staff approach to end-of-life care. This is in agreement with our results that staff reported low personcentred care in respect to the P-CAT scale "Amount of organizational and environmental support".

Studies have shown that facilitators of successful implementation of a culture change are good leadership, strong teamwork and efficient communication systems [52, 53]. A study of the implementation of person-centred care in nursing homes [54] found that effective implementation is associated with a confident leadership communication about the goals for change and the organizational readiness for change of the care providers.

A study conducted within the KUPA project explored the readiness to implement palliative care in the included nursing homes from the perspective of managers [55] and found both barriers to and facilitators for implementation. One of the barriers was fear or hesitation among the staff to face dying persons and to talk to them about existential issues. An ethnographic study in the KUPA project verified that conversations about death and dying was related to obstacles among assistant nurses [21]. To be able to talk about preferences in the end of life, to get to know the older person and create a close relationship has been highlighted as a key aspect to providing quality end-of-life care [51]. In person-centred care, it is also necessary to understand the behaviours and psychological symptoms from the perspective of the person [7]. The person and the staff need to share information and the persons should be able to participate on equal basis in decisions concerning care and treatment
[7], and the fear of death and dying thus hampers the implementation of care.

Another well-known barrier to the implementation of palliative care in nursing homes described by Nilsen et al. [55] and in other studies with the aim to improve palliative care in nursing homes $[51,56,57]$ is resources and time. Limited resources restrict the number of staffs per older person, which has an impact on the time available for communication with the older persons, their families, and colleagues, which is crucial to be able to perform person-centred care. The time the older persons spend at the nursing homes in Sweden is decreasing [4, 29] because they are frailer and often have multimorbidity and complex care needs [17] when they move there. However, it is not obvious that more staff are employed to manage the increased workload. Instead, the staff must learn and include new initiatives and/or recommendations from the organization in their practice. These initiatives are often additive to the staff's already heavy workload and might result in change fatigue. Change fatigue is the overwhelming feeling of stress, exhaustion, and burnout associated with rapid and continuous change in the workplace [58, 59]. Frequent changes in the organization can also cause a saturation effect, which occurs when there is no period of recovery between the changes in the organization [60]. Nilsen et al. [55] reported that the managers stressed that the staff were tired of changes, which made them less interested in acquiring new knowledge and skills required to develop person-centred palliative care.

Another limitation of the study is the drop-out rate due to declined continued participation, staff quitting or changed workplace, sick leave, maternal leave energy was considerable (47\%) and higher than expected, leaving us with a limited number of staff (n 365) included in the analytical part. The lessons learned from this study is to test intervention with a higher dose of training through more frequent occasions during a longer period than 6 months and provide the education to all staff at the participated nursing homes. 
In a narrative review, 24 studies from three countries [61] were compared in terms of person-centred interventions, measurement, and resident outcomes. One conclusion drawn from the study is that the concept of personcentred care is ambiguous, with no agreement upon definition, which is crucial when developing and implementing this care model. According to Ekman et al. [14], it can be difficult for staff to always put the person before the disease even if they apply person-centred care, which can be important when evaluating the result of a palliative care intervention according to person-centeredness. However, even if person-centred care has been an increasing focus in Sweden during the last years, a paradigm shift takes time and is not done overnight [14].

There is a known gap between what we know and what we do in practice in health-care [62], which has been the rationale to implement evidenced-based palliative knowledge through the KUPA project. In the ethnographic study [21] within the project concerning how nurse assistants performed existential conversations with residents at nursing homes, this gap was highlighted. The nurse assistants had tools and knowledge of how to handle questions and thoughts from the residents about dying and death, but in practice, they lacked time, and emotional strain was another obstacle preventing them from using their knowledge. Gladman et al. [62] highlighted the importance of organizational direction to get professional training, which may generate professionals with interest in and skills to transform knowledge into practice. They also proposed a collaborative non-linear, multidirectional, and iterative process of knowledge exchange that involve staff at nursing homes, not the traditional model where researchers present evidence that should be implemented in clinical practice. Therefore, the educational intervention in KUPA project was designed as a training for staff and frontline managers consisting of evidence-based knowledge in a booklet constructed for the project and reflective discussions in five seminars as well as assignments to do in preparation before each seminar or to complete after each seminar. The assignments inspired the staff to take "cases" from their daily work. A list of references for further selfstudy by the staff was also given in the booklet (Additional file 1). Rowley, Morris, Currie, and Schneider [63] have described attempts to bridge the gap between research and practice by having researchers involved in both research and clinical practice. Even Cooke, Langley, Wolstenholme, and Hampshaw [64] highlighted the importance of research as a result from co-production, but this requires time and resources to overcome boundaries and promoting leaders.

\section{Conclusions}

This study evaluated the staff's perception of providing person-centred palliative care for older persons in nursing homes after they participated in an educational palliative care intervention. The results indicated that the care and service provided at the nursing homes before the intervention had a person-centred approach, and the only perceived improvement area in personcentred care is the managers' and organization's support of the staff's everyday work in order to maintain personcentred care. The lessons learned from the study are to educate all staff at the participated nursing homes, more frequent training and use of a longer period than half a year and specifically educate some staff at each nursing home to educate newly employed staff on the personcentred palliative care approach. Not only staff needs education, but also front leaders, since the study found lack of leadership and embedded organisational support for person-centred care. Further research could focus on investigating front leaders' support to staff and removing obstacles for providing person-centred care.

\section{Additional file}

Additional file 1: The Booklet Themed meetings about palliative care within health care. (PDF $610 \mathrm{~kb}$ )

\section{Abbreviations \\ $\mathrm{Cl}$ : Confidence interval; KUPA project: Implementation of Knowledge-based Palliative Care; OR: Odds ratio; P-CAT: Person-centred Care Assessment Tool; PCQ-S: Person-Centred Climate Questionnaire for staff; WHO: World Health Organization}

\section{Acknowledgements}

We would like to thank Anna Axmon, Associate Professor, Lund University, Lund, Sweden, for valuable statistical advice. Finally, we would like to thank Magnus Persson, PhD, Research administrator and Helene Åvik Persson, RN, PhD student, for sending out and coding the questionnaires.

\section{Authors' contributions}

CB conducted the analysis and drafted the article. The project leader GA developed the design, administered (PI) the national research grant, monitored the recruiting, contributed to the analysis, and furthermore performed a critical revision of the results. BW and LB facilitated the recruiting of participants and the data collection. All authors contributed to the content of the manuscript text, read, discussed, and approved the final manuscript.

\section{Funding}

We would like to acknowledge grants from the Swedish Research Council; the Vårdal Foundation; the Gyllenstierna Krapperup's Foundation; Medical Faculty, Lund University; the City of Lund; Faculty of Health and Life Sciences, Linnaeus University; the Greta and Johan Kock Foundation and the Ribbingska Memorial Foundation. The funders were neither involved in the study design, data collection, analysis, interpretation of data, nor in writing the manuscript.

\section{Availability of data and materials}

Even though the data are anonymized, the study contains sufficient details to enable identification of individuals. Therefore, before approving the study, the Regional Ethics Review Board in Lund set severe restrictions regarding the accessibility of the data, but they are available from the project leader (GA) on reasonable request. Written permission to share or distribute the booklet can be received by Associate Professor Anna Sandgren, Center for Collaborative Palliative Care, Linnaeus University, Sweden. E-mail: anna.sandgren@Inu.se 
Most Photos $A B$ has granted permission to use the image on the first page to Gerd Ahlström.

\section{Ethics approval and consent to participate}

The KUPA project was approved by the Regional Ethics Review Board in Lund (reference number: 2015/4). The study was guided by the research ethical principles for medical research [65] and conducted in accordance with the Swedish Ethical Review of Research Involving Humans Act [66] and the General Data Protection Regulation [GDPR] [67].

Prior to the interviews, the staffs were given verbal and written information about the study so that they could make an autonomous decision whether to partake in the study. Written consent was obtained from participants. Participation was voluntary and could be terminated at any time without having to give a reason and without any consequences. To maintain the principle of non-maleficence, the staff were guaranteed confidentiality i.e. the data collected were encoded so that individuals cannot be identified. Codes replaced the staff personal data. Only the codes were used during the analysis, and the findings are reported on group level. The code lists are stored in locked cabinets apart from the questionnaire forms.

\section{Consent for publication}

Not applicable.

\section{Competing interests}

The authors declare that they have no competing interests.

\section{Author details}

'Department of Health Sciences, Faculty of Medicine, Lund University, P.O. Box 157, SE-221 00 Lund, Sweden. ${ }^{2}$ Department of Health and Caring Sciences, Faculty of Health and Life Sciences, Centre for Collaborative Palliative Care Linnaeus University, Växjö, Sweden.

\section{Received: 10 September 2018 Accepted: 20 May 2019} Published online: 31 May 2019

\section{References}

1. Hall S, Petkova H, Tsouros A, Constantini M, Higginson I. Palliative care for older people: better practices. Copenhagen: WHO regional Office for Europe. 2011. Accessed 4 Jul 2018. http://www.euro.who.int/_data/assets/ pdf_file/0017/143153/e95052.pdf

2. Houttekier D, Cohen J, Bilsen J, Addington-Hall J, Onwuteaka-Philipsen BD, Deliens L. Place of death for older persons with dementia. A study in five European countries. J Am Geriatr Soc. 2010. https://doi.org/10.1111/j.15325415.2010.02771.x

3. Håkanson C, Öhlén J, Morin L, Cohen J. A population-level study of place of death and associated factors in Sweden. Scand J Public Health. 2015. https://doi.org/10.1177/1403494815595774.

4. Smedbäck J, Öhlén J, Årested K, Alvariza A, Fürst CJ, Håkanson C. Palliative care during the final week of life of older people in nursing homes: a register-based study. Palliat Support Care. 2017. https://doi.org/10.1017/ S1478951516000948.

5. Davies E, Higginson IJ. Better palliative care for older people. Copenhagen: WHO Regional Office for Europe; 2004. Accessed 12 Oct 2017. http://www. euro.who.int/_data/assets/pdf_file/0009/98235/E82933.pdf

6. Seymour J. Changing times: preparing to meet palliative needs in the 21st century. Br J Community Nurs. 2011. https://doi.org/10.12968/bjcn. 2011.16.1.18.

7. McCormack B, McCance TV. Development of a framework for personcentred nursing. J Adv Nurs. 2006. https://doi.org/10.1111/j.1365-2648.2006. 04042.x.

8. National Board of Health and Welfare. The national knowledge support document for good palliative care at the end of life. [in Swedish: Nationellt kunskapsstöd för god palliativ vård i livets slutskede - Vägledning, Rekommendationer och indikatorer - Stöd för styrning och ledning]. Stockholm: Sweden. 2013. Accessed 4 Jul 2018. https://www.socialstyrelsen. se/Lists/Artikelkatalog/Attachments/19107/2013-6-4.pdf

9. Saunders CM, Kastenbaum R. Hospice care on the international scene. New York, NY: Springer Pub. Co; 1997.

10. World Health Organization. National cancer control programs: policies and managerial guidelines. 2nd ed. Geneva; 2002. https://apps.who.int/iris/
bitstream/handle/10665/42494/9241545577.pdf;jsessionid=E769D128437799 DF1EB646328ECE425F?sequence=1. Accessed 22 May 2019.

11. Dewing J. Concerns relating to the application of frameworks to promote person-centeredness in nursing with older people. J Clin Nurs. 2004. https:// doi.org/10.1111/j.1365-2702.2004.00925.x.

12. McCormack B. A conceptual framework for person-centred practice with older people. Int J Nurs Pract. 2003. https://doi.org/10.1046/j.1440-172X. 2003.00423.x.

13. McCormack B, Karlsson B, Dewing J, Lerdal A. Exploring personcenteredness: a qualitative meta-synthesis of four studies. Scand J Caring Sci. 2010. https://doi.org/10.1111/j.1471-6712.2010.00814.x.

14. Ekman I, Swedberg K, Taft C, Lindseth A, Norberg A, Brink E, et al. Personcentred care - ready for prime time. Eur J Cardiovasc Nurs. 2011. https://doi. org/10.1016/j.ejcnurse.2011.06.008.

15. Froggatt K, Payne S, Morbey H, Edwards M, Finne-Soveri H, Gambassi G, et al. Palliative care development in European care homes and nursing homes: application of a typology of implementation. J Am Med Dir Assoc. 2017. https://doi.org/10.1016/j.jamda.2017.02.016.

16. Brännström $M$, Hägglund L, Fürst $C J$, Boman K. Unequal care for dying patients in Sweden: a comparative registry study of deaths from heart disease and cancer. Eur J Cardiovasc Nurs. 2012. https://doi.org/10.1016/j. ejcnurse.2011.06.007.

17. Wowchuk SM, McClement S, Bond J. The challenge of providing palliative care in nursing homes part II internal factors. Int J Palliat Nurs. 2007. https:// doi.org/10.12968/ijpn.2007.13.7.24346.

18. Handley M, Goodman C, Froggatt K, Mathie E, Gage H, et al. Living and dying: responsibility for end-of-life care in care homes without on-site nursing provision - a prospective study. Health Soc Care Communit. 2014. https://doi.org/10.1111/hsc.12055.

19. Johnson M, Attree M, Jones J, Al Gamal E, Garbutt D. Diagnosis, prognosis, and awareness of dying in nursing homes: towards the gold standard? Int J Older People Nursing. 2014. https://doi.org/10.1111/opn.12024.

20. Österlind J, Ternestedt B-M, Hansebo G, Hellström I. Feeling lonely in an unfamiliar place: older people's experiences of life close to death in nursing home. Int J Older People Nursing. 2017. https://doi.org/10.1111/opn.12129.

21. Alftberg $\AA$, Ahlström G, Nilsen P, Behm L, Sandgren A, Benzein E, et al. Conversations about death and dying with older people: an ethnographic study in nursing homes. Healthcare. 2018. https://doi.org/10.3390/ healthcare6020063.

22. Fryer S, Bellamy G, Morgan T, Gott M. Sometimes I've gone home feeling that my voice hasn't been heard, a focus group study exploring the views and experiences of health care assistants when caring for dying residents. BMC Palliative Care. 2016. https://doi.org/10.1186/s12904-016-0150-3.

23. Goddard C, Stewart F, Thompson G, Hall S. Providing end-of-life care in care homes for older people: a qualitative study of the views of care home staff and community nurses. J Appl Gerontol. 2013. https://doi.org/10.1177/ 0733464811405047

24. Brazil K, Brink P, Kaasalainen S, Kelly ML, McAiney C. Knowledge, and perceived competence among nurses caring for the dying in long-term care homes. Int J Palliat Nurs. 2012. https://doi.org/10.12968/ijpn.2012.18.2.77.

25. Bruera E, Willey JS, Ewert-Flanagan PA, Cline MK, Kaur G, Shen L, et al. Pain intensity assessment by bedside nurses and palliative care consultants: a retrospective study. Support Care Cancer. 2005. https://doi.org/10.1007/ s00520-004-0692-4.

26. Levine S, O'Malley S, Baron A, Ansari A, Deamant C, Frader J, et al. Training the workforce: description of a longitudinal interdisciplinary education and mentoring program in palliative care. J Pain Symptom Manag. 2017. https:// doi.org/10.1016/j.jpainsymman.

27. Andersson S, Årestedt K, Lindqvist O, Fürst CJ, Brännström M. Factors associated with symptom relief in end-of-life care in residential care homes: a national register-based study. J Pain Symptom Manag. 2018. https://doi. org/10.1016/j.jpainsymman.2017.12.489.

28. Ahlström G, Nilsen P, Benzein E, Behm L, Wallerstedt B, Persson M, Sandgren A. Implementation of knowledge-based palliative care in nursing homes and pre-post evaluation by cross-over design: a study protocol. BMC Palliative Care. 2018. https://doi.org/10.1186/s12904-018-0308-2.

29. National board of health and welfare. Statistik om särskilt Boende (statistics for nursing homes). [in Swedish]. 2016a. Accessed 4 Jul 2018. http://www. socialstyrelsen.se/Lists/Artikelkatalog/Attachments/20404/2016-12-5.pdf

30. Schon $\mathrm{P}$, Lagergren $\mathrm{M}$, Karleholt I. Rapid decrease in length of stay in institutional care for older people in Sweden between 2006 and 2012: 
results from a population-based study. Health Soc Care Community. 2016. https://doi.org/10.1111/hsc.12237.

31. National Board of Health and Welfare Vård och omsorg om äldre. Lägesrapport 2016. (care and service for elderly. Progress report 2016). [in Swedish]. (2016b). Accessed 4 Jul 2018. https://www.socialstyrelsen.se/Lists/ Artikelkatalog/Attachments/20088/2016-2-29.pdf

32. Regional Cancer Centres in co-operation (Regionala cancercentrum i samverkan). The national care program for palliative care 2012-2014. [in Swedish]. 2012.

33. Connor R, Sepulveda Bermedo MC. Global atlas of palliative Care at the end of life. Worldwide palliative care Alliance. 2014. Accessed 11 June 2018. http://www.who.int/nmh/Global_Atlas_of_Palliative_Care.pdf

34. Sjögren $K$, Lindkvist $M$, Sandman PO, Zingmark K, Edvardsson D. Psychometric evaluation of the Swedish version of the person-centred care assessment tool (P-CAT). Int Psychogeriatr. 2012. https://doi.org/10.1017/ S104161021100202X

35. Edvardsson D, Fetherstonhaugh D, Nay R, Gibson S. Development, and initial testing of the person-centred care assessment tool (P-CAT). Int Psychogeriatr. 2010. https://doi.org/10.1017/\$1041610209990688.

36. Edvardsson D, Sandman PO, Rasmussen B. Construction, and psychometric evaluation of the Swedish language person-centred climate questionnaire - staff version. J Nurs Manag. 2009. https://doi.org/10.1111/j.1365-2834.2009.01005.x.

37. Öhlén J, Reimer-Kirkham S, Astle B, Håkansson C, Lee J, Eriksson M, Sawatzky R. Person-centred care dialectics - inquired in the context of palliative care. Nurs Philos. 2017. https://doi.org/10.1111/nup.12177.

38. Cherny NI, Fallon MT, Kaasa S, Portenoy RK, Currow DC. Oxford textbook of palliative medicine. 5th ed. New York, NY: Oxford University Press; 2015.

39. Seymour JE, Kumar A, Froggatt K. Do nursing homes for older people have the support they need to provide end-of-life care? A mixed method enquiry in England. Palliat Med. 2011. https://doi.org/10.1177/ 0269216310387964.

40. Lavoie M, Blondeau D, Martineau I. The integration of a person-centred approach in palliative care. Palliat Support Care. 2013. https://doi.org/10. 1017/S1478951512000855.

41. Grassi L. Communicating anticancer treatment cessation and transition to palliative care: the need for a comprehensive and culturally relevant, person-centred approach. Cancer. 2015. https://doi.org/10.1002/cncr.29638.

42. Rokstad AMM, Engedal K, Edvardsson D, Selbæk G. Psychometric evaluation of the Norwegian version of the person-centred care assessment tool. Int J Nurs Pract. 2012. https://doi.org/10.1111/j.1440-172X.2011.01998.x.

43. Jacobsen FF, Mekki TE, Førland O, Folkestad B, Kirkevold Ø, Skår R, et al. A mixed method study of an education intervention to reduce use of restraint and implement person-centered dementia care in nursing homes. BMC Nurs. 2017. https://doi.org/10.1186/s12912-017-0244-0.

44. Røen I, Kirkevold Ø, Testad I, Selbæk G, Engedal K, Bergh S. Person-centred care in Norwegian nursing homes and its relation to organizational factors and staff characteristics: a cross-sectional survey. Int Psychogeriatr. 2017. https://doi.org/10.1017/S1041610217002708.

45. Edvardsson D, Sandman PO, Borell L. Implementing national guidelines for person-centred care of people with dementia in residential aged care: effects on perceived person-centeredness, staff strain, and stress of conscience. Int Psychogeriatr. 2014. https:/doi.org/10.1017/S1041610214000258.

46. Edvardsson D, Sjögren K, Lindkvist M, Taylor M, Edvardsson K, Sandman PO. Person-centred climate questionnaire (PCQ-S): establishing reliability and cut-off scores in residential aged care. J Nurs Manag. 2015. https://doi.org/ 10.1111/jonm.12132

47. Hall S, Kolliakou A, Petkova H, Froggatt K, Higginson IJ. Interventions for improving palliative care for older people living in nursing care homes. Cochrane Database Syst Rev. 2011. https:/doi.org/10.1002/14651858.CD007132.pub2.

48. Froggatt KA. Palliative care and nursing homes: where next? Palliat Med. 2001. https://doi.org/10.1191/026921601671222652.

49. Casey D, Murphy K, Ni Leime A, Larkin P, Payne S, Froggatt KA, O'Shea E. Dying well: factors that influence the provision of good end-of-life care for older people in acute and long-stay care settings in Ireland. J Clin Nurs. 2011. https://doi.org/10.1111/j.1365-2702.2010.03628.x.

50. Clarke A, Ross H. Influences on nurses' communications with older people at the end of life: perceptions and experiences of nurses working in palliative care and general medicine. Int J Older People Nursing. 2006 https://doi.org/10.1111/j.1748-3743.2006.00006.x.

51. Hopkinson JB, Hallett CE, Luker KA. Caring for dying people in hospital. J Adv Nurs. 2003. https://doi.org/10.1046/j.0309-2402.2003.02836.x.
52. Barba BE, Tesh AS, Courts NF. Promoting thriving in nursing homes: the Eden alternative. J Gerontol Nurs. 2002;28:7-13.

53. Steiner $J$, Eppelheimer C, De Vries M. Successful Edenization through education: suggestions for encouraging LTC staff to embrace the change of the Eden alternative. Nurs Homes. 2004;53:46-9.

54. Rosemond CA, Hanson LC, Ennett ST, Schenck AP, Weiner BJ. Implementing person-centred care in nursing homes. Health Care Manag Rev. 2012. https://doi.org/10.1097/HMR.0b013e318235ed17.

55. Nilsen P, Wallerstedt B, Behm L, Ahlström G. Towards evidence-based palliative care in nursing homes in Sweden: a qualitative study informed by the organizational readiness to change theory. Implement Sci. 2018. https:// doi.org/10.1186/s13012-017-0699-0.

56. Brueckner T, Schumacher M, Schneider N. Palliative care for older people-exploring the views of doctors and nurses from different fields in Germany. BMC Palliat Care. 2009. https://doi.org/10.1186/1472-684X-8-7.

57. Lynch T, Clark D, Centeno C, Rocafort J, de Lima L, Filbet M, et al. Barriers to the development of palliative care in Western Europe. Palliat Med. 2010. https://doi.org/10.1177/0269216310368578.

58. Bernerth BB, Walker HJ, Harris SG. Change fatigue: development and initial validation of a new measure. Work Stress. 2011. https://doi.org/10.1080/ 02678373.2011 .634280

59. Brown $\mathrm{R}$, Wey $\mathrm{H}$, Foland $\mathrm{K}$. The relationship among change fatigue, resilience, and job satisfaction of hospital staff nurses. J Nurs Scholarsh 2018, https://doi.org/10.1111/jnu.12373

60. Ead $\mathrm{H}$. Change fatigue in health care professionals - an issue of workload or human factors engineering? J Perianesth Nurs. 2015. https://doi.org/10. 1016/j.jopan.2014.02.007

61. Li J, Porock D. Resident outcomes of person-centered care in long-term care: a narrative review of interventional research. Int J Nurs Stud. 2014. https://doi.org/10.1016/j.ijnurstu.2014.04.003.

62. Gladman JR, Conroy SP, Ranhoff AH, Gordon AL. New horizons in the implementation and research of comprehensive geriatric assessment: knowing, doing and the 'know-do' gap. Age Ageing. 2016. https://doi.org/ 10.1093/ageing/afw012.

63. Rowley E, Morriss R, Currie G, Schneider J. Research into practice: collaboration for leadership in applied Health Research and care (CLAHRC) for Nottinghamshire, Derbyshire, Lincolnshire (NDL). Implement Sci. 2012. https://doi.org/10.1186/1748-5908-7-40.

64. Cooke J, Langley J, Wolstenholme D, Hampshaw S. Seeing" the difference: the importance of visibility and action as a mark of "authenticity" in coproduction comment on "collaboration and co-production of knowledge in healthcare: opportunities and challenges. Int J Health Policy Manag. 2016. https://doi.org/10.15171/ijhpm.2016.136.

65. World Medical Association. WMA Declaration of Helsinki - Ethical principles for medical research involving human subjects. Fortaleza: WMA General Assembly; 2013

66. SFS 2003:460. Lag om etikprövning av forskning som avser människor. (Act concerning the ethical review of research involving humans). Stockholm, ministry of education and research; 2003.

67. Board EDP. the General Data Protection Regulation GDPR; 2018.

\section{Publisher's Note}

Springer Nature remains neutral with regard to jurisdictional claims in published maps and institutional affiliations.

Ready to submit your research? Choose BMC and benefit from:

- fast, convenient online submission

- thorough peer review by experienced researchers in your field

- rapid publication on acceptance

- support for research data, including large and complex data types

- gold Open Access which fosters wider collaboration and increased citations

- maximum visibility for your research: over $100 \mathrm{M}$ website views per year

At $\mathrm{BMC}$, research is always in progress.

Learn more biomedcentral.com/submissions 